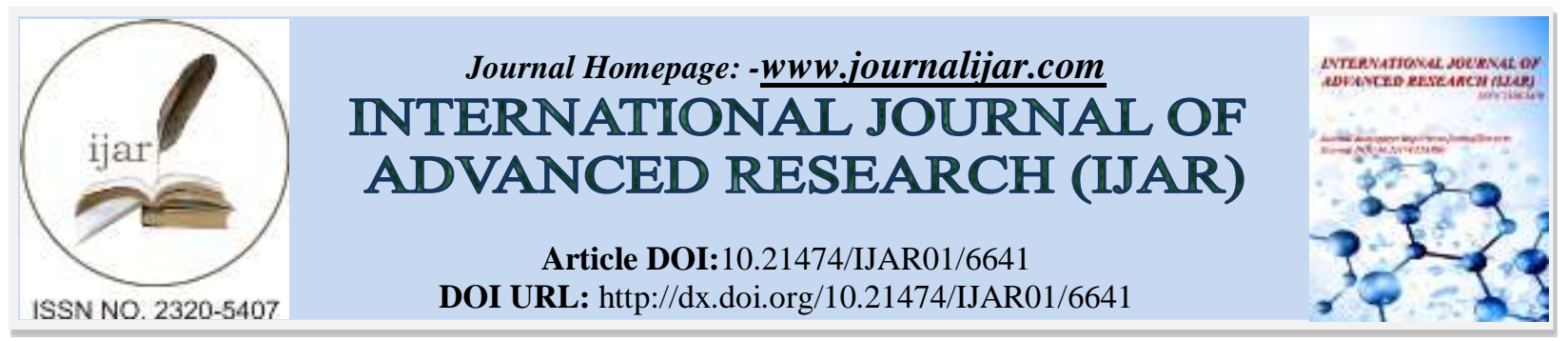

RESEARCH ARTICLE

\title{
CARICA PAPAYA: A BOTANICAL TREATMENT FOR PATIENTS WITH DENGUE VIRUS INFECTION.
}

\author{
Elton Mathias, Roveena Goveas and Manish Rajak.
}

\section{Manuscript Info}

(.........................

Manuscript History

Received: 02 January 2018

Final Accepted: 04 February 2018

Published: March 2018

Keywords:-

Dengue, Carica papaya, flavovirus serotypes.

\section{Abstract}

Dengue is a mosquito borne viral disease caused any one of four closely related but antigenically distinct flavovirus serotypes, DENV 1 through 4 . Its spectrum ranges from asymptomatic infection to dengue fever (DF), dengue hemorrhagic fever (DHF), and dengue shock syndrome (DSS), and may lead to patient death. It is known that the platelet count drops in dengue patients after the first three days of fever and the gradually increases after the seventh day or drop further with derangement of other clotting factors to develop into dengue hemorrhagic state [1]. Dengue Haemorrhagic Fever (DHF), a potentially lethal complication, was first recognized in the 1950s during dengue epidemics in the Philippines and Thailand. Dengue fever is now an international public health concern, affecting individuals from countries even where the disease is not prevalent, especially spread by global travellers from endemic areas to non-endemic areas [2].

Despite the advancement of knowledge and technology in the field of medicine, no sure cure or vaccine has yet been devised to combat the dengue virus, which has the ability to create a viral epidemic of epic proportions. The aim of this review is to capture the progress made in elucidating the botanical compounds responsible for anti-DENV activity of Carica papaya.

Copy Right, IJAR, 2018,. All rights reserved.

\section{Introduction:-}

The use of plants for medicinal purposes dates back to ancient times. The papaya plant (Carica papaya Linn.) is known for its nutritional value throughout the world, and the leaves have been used in folk medicine for centuries, for various diseases. During the last few decades, research has validated its medicinal use in treating several conditions. Some of Its beneficial effects include anti-inflammatory, wound healing, anti-tumour and immunemodulatory effects, antioxidant, antifungal [3], antimicrobial [4,5], hypoglycemic [6]. Leaves of Carica papaya are non-toxic and safe for oral consumption [7]. Of importance, is the use of this leaf in patients with Dengue fever.

Dr. Sanath Hettige, in 2008 conducted the first documented pilot study in 12 patients (a mix of adult and pediatric patients), confirmed with dengue fever during a dengue outbreak in Sri Lanka. The patients were administered nondiluted C. papaya leaf juice in two doses every 8 hours. Blood samples and clinical conditions were assessed before and after administering the juice. Drugs which were likely to alter the platelet count were not administered on these patients. The platelet counts and the total white cell counts had increased in all patients within 24 hours after administering papaya leaf juice. Five patients reported that an itching haemorrhagic skin rash (platelet count < 100000) disappeared within two days of treatment. [8] 
Isolated case studies have shown that Carica papaya leaf extracts have successfully improved platelet counts within 5 consecutive days of administration. [9,10] When taken twice a day papaya leaf juice helps to increase white blood cells and platelets, normalizes clotting, and repairs the liver. [11]

Subenthran et al., in 2013 showed via gene expression that the Arachidonate 12-lipoxygenase (ALOX-12) and Platelet-Activating Factor Receptor (PTAFR) genes was higher expressed among leaf extract treated patients as compared to the non-treated patients. While the PTAFR gene is responsible for increased platelet production and aggregation, ALOX 12, a platelet specific gene, is known to be associated with increased megakaryocyte production as well as its conversion to platelets through 12-HETE mediated pathway which in turn leads to increased platelet production. [12] A significant increase in the mean platelet count was noted after 40 hours and 48 hours of leaf juice consumption. The PTAFR gene which is known to be responsible for increased platelet production and aggregation was expressed 13.42-folds among the patients who consumed the juice as compared to the control group indicating that the juice had played an important role in addressing the arresting of bleeding tendencies among these patients. [13]

According to Senthilvel, based on bioinformatics tools, it was shown that the flavonoid quercetin, isolated from the leaves would exert anti-Dengue activity. The study analysed the activity of compounds in Carica papaya leaf extracts against NS2B-NS3 serine protease of DENV2 virus. Quercetin showed potential inhibitory activity against NS2B-NS3 serine protease. Further ADME and toxicity risk assessment strongly suggested that quercetin did have marked antiviral activity against DENV2 virus by blocking the viral assembly mechanism of DENV2 virus.[14] Nugroho in 2017 [15], identified seven flavonoids which included quercetin 3-(2G-rhamnosylrutinoside), kaempferol 3-(2G-rhamnosylrutinoside), quercetin 3-rutinoside, myricetin 3-rhamnoside, kaempferol 3-rutinoside, quercetin and kaempferol were isolated from the leaves of C. papaya. [16]

Head and Lauter in 1956 reported the presence of flavonols, tannins, organic acids, alkaloids [17], trace unsaturated sterols [18] and glycosides [19]. Other studies have also shown the presence of saponins, flavonoids, phenols, protein, amino acid, steroid, anthraquinones and terpenoids [20]. These leaves are also rich sources of vitamins such as thiamine (B1), riboflavin (B2), ascorbic acid (C), and minerals such as calcium, magnesium, sodium, potassium and manganese.[21]

Based on the positive outcomes of various research, Akhila and Vijayalakshimi, in 2015 attempted to further characterise constituents, using Liquid Chromatography-Mass Spectroscopy (LCMS). Identified constituents are provided in Table 1.[22]

\begin{tabular}{|c|c|c|}
\hline o. & Compond name & Molecular mass \\
\hline & Tocopherol & 430.72 \\
\hline & Ascorbic acid & 176.13 \\
\hline & Carpaine & 466.71 \\
\hline & Deoxykacmpferol & 270.25 \\
\hline & Kaempferol & 286.24 \\
\hline & Deoxyquercetin & 286.25 \\
\hline & Quercetin & 302.24 \\
\hline & Dicoumarol & 336.31 \\
\hline & Coumasoylquinic acid & 338.32 \\
\hline & Coumarin & 146.15 \\
\hline & Folic acid & 441.41 \\
\hline & Cystine & 121.16 \\
\hline & Homocystcine & 135.19 \\
\hline & Cysteine sulptoxide & 177.22 \\
\hline & L Glutamic acid & 147.13 \\
\hline & p. Coumaroyl alcohol & 150.18 \\
\hline & dimethoxy phenol & 154.17 \\
\hline & umbelliferoae & 162.15 \\
\hline & phenylalanine & 165.19 \\
\hline & Caffeoyl alcobol & 166,18 \\
\hline & Methyl nonyl ketone & 170.30 \\
\hline
\end{tabular}




\section{Conclusion:-}

Treatment for dengue is usually symptomatic. Some cases require platelet transfusions and fluid management [23]. One of the most disturbing aspects of the problem of dengue is that there are no effective antiviral agents available to treat dengue complications. Though symptomatic treatment works in most mild cases, some cases progress to complications very fast and this often make it difficult to save the life of the patient. The most severe form of dengue is the hemorrhagic form, This may be the reason a lot of effort has been put into mediating this specific symptom.

As yet research and several clinical trials have indicated that $C$. Papaya leaves can be used in addition to existing treatment, especially in patients with DHF, by increasing the platelet count, and shortening the hospitalisation period. Being easily available and affordable, the use of papaya leaves seems to be occurring indiscriminately, where available. Sarala and Pakinkar in 2014, and Ansari in 2016 [24], both expressed concern that besides a handful of clinical trials and with capsules containing the extract in India, there is no consistent data available on the mode of preparation, pharmacokinetic properties and he absorption of the active ingredient. However, further investigations are required to gain insight into standardizing this very promising treatment.

\section{References:-}

1. Onkar Singh and M. Ali. Phytochemical and antifungal profiles of the seeds of Carica papaya L. Indian J Pharm Sci. 2011;73(4):447-451. doi: 10.4103/0250-474X.95648.

2. Alorkpa EJ, Boadi NO, Badu M, Saah SA. Phytochemical screening, antimicrobial and antioxidant properties of assorted Carica papaya leaves in Ghana. J Med Plants Stud. 2016;4(6):193-198.

3. Yahaya A, Ali M, Idris A. Antibacterial activity and phytochemical screening of Carica papaya on some enteric bacterial isolates of public health importance. Greener Journal of Biological Sciences. 2017;7 (1):001-007. (DOI: http://doi.org/10.15580/GJBS.2017.1.122916224).

4. Isela E.Juárez-Rojopa, Carlos A.Tovilla-Zárate, Dora E.Aguilar-Domínguez, Luis F. Roa-de laFuente, Carlos E.Lobato-García, Jorge L.Blé-Castillo, LeonorLópez-Meraz, Juan C.Díaz-Zagoya, Deysi Y.Bermúdez-Ocaña. Phytochemical screening and hypoglycemic activity of Carica papaya leaf in streptozotocin-induced diabetic rats. Revista Brasileira de Farmacognosia. 2014;24(3):341-347.

5. Subenthiran S, Choon TC, Cheong KC, Thayan R, Teck MB, Muniandy PK, Afzan A, Abdullah NR, and Ismail Z. Carica papaya leaves juice significantly accelerates the rate of increase in platelet count among patients with dengue fever and dengue haemorrhagic fever. Evid Based Complement Alternat Med. 2013. http://dx.doi.org/10.1155/2013/616737.

6. World Health Organization prevention and control of dengue haemorrhagic fever: diagnosis, treatment, Comprehensive guidelines. World Health Organization Regional Publication 1999, SEARO, No.29.

7. Gowda AC, Kumar NV, Kasture PN, Nagabushan KH. A pilot study to evaluate the effectiveness of Carica papaya leaf extract in increasing the platelet count in cases of dengue with thrombocytopenia. Indian Medical Gazette. 2014.

8. S Hettige. Salutary effects of Carica papaya leaf extract in dengue fever patients - a pilot study. Sri Lankan Family Physician, 2008;29:17-19.

9. Osama Siddique, Ayesha Sundus, Mohammad Faisal Ibrahim. Effects of papaya leaves on thrombocyte counts in dengue - a case report. Journal of Pakistan Medical Association. 2014;64(3).

10. Ahmad N, Fazal H, Ayaz M, Abbasi BH, Mohammad I, Fazal L. Dengue fever treatment with Carica papaya leaves extracts. Asian Pac J Trop Biomed 2011;1:330-333.

11. Aravind, Debjit. Traditional and Medicinal Uses of Carica papaya. J Med Plants Stud. 2013; 1(1) SSN: 23203862.

12. Subenthiran S, Choon TC, Cheong KC, et al., Carica papaya leaves juice significantly accelerates the rate of increase in platelet count among patients with dengue fever and dengue haemorrhagic ever. Evid Based Complement Alternat Med. 2013. doi:10.1155/2013/616737.

13. Subenthiran S, Choon TC, Cheong KC, et al. Carica papaya leaves juice significantly accelerates the rate of increase in platelet count among patients with dengue fever and dengue haemorrhagic fever. Evid Based Complement Alternat Med. 2013;2013:616737. doi: 10.1155/2013/616737.

14. Senthilvel P, Lavanya P, Kumar KM, Swetha R, Anitha P, Bag S, Sarveswari S, Vijayakumar V, Ramaiah S, and Anbarasu A. Flavonoid from Carica papaya inhibits NS2B-NS3 protease and prevents Dengue 2 viral assembly. Bioinformation. 2013; 9(18): 889-895. 
15. AgungNugroho, HestyHeryani, Jae SueChoi, Hee-JuhnPark. Identification and quantification of flavonoids in Carica papaya leaf and peroxynitrite-scavenging activity. Asian Pac J Trop Biomed. 2017; 7(3):208-213. https://doi.org/10.1016/j.apjtb.2016.12.009.

16. Zunjar V, Mammen D, Trivedi BM, Daniel M. Pharmacognostic, physicochemical and phytochemical studies on Carica papaya Linn. leaves. Pharmacognosy Journal, 2011; 3(20):5-8. doi:10.5530/pj.2011.20.2.

17. W. F. HeadW. M. Lauter. Phytochemical examination of the leaves of Carica papaya L. Economic Botany. 1956;10(3):258-260.

18. Ikeyi Adachukwu P, Ogbonna Ann O and Eze Faith U Phytochemical analysis of paw-paw (Carica papaya) leaves.' Int. J. LifeSc. Bt Pharm. Res. 2013;2(3).

19. Yahaya A, Ali M. and Idris A. Antibacterial activity and phytochemical screening of Carica papaya on some enteric bacterial isolates of public health importance. Greener Journal of Biological Sciences. 2017;7 (1):001007. (DOI: http://doi.org/10.15580/GJBS.2017.1.122916224).

20. P.B. Ayoola and A. Adeyeye. Phytochemical and nutrient evaluation of Carica papaya (paw paw) leaves. IJRRAS 2010;5(3).

21. S. Akhila and N. G. Vijayalakshmi. Phytochemical studies on Carica papaya leaf juice. IJPSR, 2015;6(2): 880883.

22. Guidelines in using carica papaya leaf extract for Dengue fever patients.BMJ 2015; 351 doi: https://doi.org/10.1136/bmj.h4661 (Published 15 September 2015).

23. Hynes N.A. - Dengue: A reemerging concern for travelers. Cleve Clin J Med. 2012;79:474-482.

24. Ansari RM. Extract of Carica papaya L. leaves: Standardising its use in dengue fever. Indian J Pharmacol. 2016; 48(3): 338-339. 